\title{
Hawksbill turtles still endangered
}

Sir - In a recent Commentary article ${ }^{1}$, Nicholas Mrosovsky criticized the International Union for the Conservation of Nature (IUCN) for the lack of documentation supporting the listing of the hawksbill turtle (Eretmochelys imbricata) as 'critically endangered' in the 1996 IUCN Red List of Threatened Animals.

The listing of the hawksbill as critically endangered was based on a rigorous evaluation by IUCN Marine Turtle Specialist Group members involved in preparing the status justification. I am a member of that group, and a hawksbill specialist. Population declines of $80 \%$ over three generations are evident or can be inferred in all ocean basins throughout the species' circumtropical range. The species has been listed by IUCN as endangered since 1968.

Publication of a summary of all the data considered in the listing process is timeconsuming, and our working group (all volunteers) is moving forward as fast as possible. It should be pointed out that all the documents we are reviewing are freely available in the literature, including a 601-page review of the hawksbill's status ${ }^{3}$ sponsored by the Convention on International Trade in Endangered Species of Wild Fauna and Flora (CITES).

An unfortunate effect of Mrosovsky's Commentary will be to impart doubt that the hawksbill deserves listing as critically endangered. A few facts are in order. Population declines of the hawksbill have occurred against a backdrop of high levels of international trade in hawksbill shell (tortoiseshell).

Estimates of tortoiseshell imports into Japan from 1970 to 1992 (when Japan stopped trading) exceeded 754 tonnes, representing approximately 712,000 hawksbills. In 1990, hawksbill experts meeting in Nagasaki, Japan, estimated that there were approximately 15,000 hawksbills nesting annually worldwide.

Exploitation of hawksbills for tortoiseshell, meat and eggs continues worldwide. Perhaps the most striking indication of the hawksbill's plight is a recent communication by Colin Limpus of the Queensland Department of

Environment and Heritage, that researchers in the Solomon Islands are discovering that more than $90 \%$ of the nesting hawksbills are first-time breeders (identified by laparoscopy). Thus most females of this long-lived species are not surviving to nest for more than one season.

The only "controversy" about the hawksbill's status is that being created by those who wish to resume international trade in this species. The Cuban hawksbill proposal presented at the CITES meeting in Zimbabwe last June would have allowed resumption of the harvest of wild hawksbills to supply the luxury tortoiseshell trade between Cuba and Japan. It would also have allowed the sale of all hawksbill shell stockpiled by Cuba since 1992. Both actions would have signalled the resurrection of the destructive tortoiseshell market, which took decades to shut down. Ironically, Japan's need for Cuban stockpile was not even clear - the reported inventory of tortoiseshell in Japan in 1995 was 188 tonnes.

The Cuban hawksbill proposal was defeated, but those who orchestrated its presentation in Zimbabwe are already positioning themselves for their next attempt to reopen the trade in tortoiseshell. Mrosovsky's suggestion that hawksbills should be placed in the 'data deficient' category in the Red List is an obfuscating tactic and is appalling in its transparency. Anne Meylan

Florida Department of

Environmental Protection,

Florida Marine Research Institute,

100 8th Avenue SE,

St Petersburg, Florida 33701-5095, USA

e-mail:meylan_a@harpo.dep.state.fl.us

1. Mrosovsky, N. Nature 389, 436 (1997).

2. Baillie, J. \& Groombridge, B. IUCN Red List of Threatened Animals (IUCN, Gland, Switzerland, 1996).

3. Groombridge, B. \& Luxmoore, R. The Green Turtle and Hawksbill World Status, Exploitation and Trade (Secretariat of CITES, Lausanne, Switzerland, 1989).

\section{Animal experimentation} needs dissection

Sir - Ehsan Masood draws attention to the concern, focused by the intention of the UK government to tighten the law on animal experimentation, that research using animals may be curtailed (Nature 389, 896; 1997).

This follows an earlier account of the forthcoming Swiss referendum about the use of transgenic animals (Nature 389, 103; 1997) which expresses the fear that public opinion will lead to a ban, with consequent constraint on biological research. This is pertinent because genetically manipulated animals form an increasing proportion of the total used in experimental procedures.

One problem is that lay perceptions of transgenic animals may be coloured by the organisms that are featured in the popular media - obese, hairless and even luminescent mice — so that the public may get the impression that all genetically engineered organisms are grotesque or bizarre.

We have recently completed a survey of the views of 778 school and college students about the use of transgenic animals in medical research. Overall, $42 \%$ of our sample thought that genetic engineering of laboratory animals for this purpose was wrong, the same proportion that thought using 'ordinary' animals was wrong, suggesting that students find the process of genetically engineering animals for medical research no more or less objectionable than the use of animals in general for such research.

Few students (13\%) thought that animal research was acceptable if the animals were caused pain.

It is significant, then, that $19 \%$ of the students thought that genetically engineered laboratory animals would be in constant pain, although fewer (12\%) of the oldest group, the college students aged $16-19$, believed this. On the other hand, $49 \%$ overall imagined that use of genetically engineered animals would lead to novel discoveries, and this view increased in the college students to $57 \%$, suggesting that there might be an increasing appreciation of the value of transgenic organisms to research.
If our figures, showing that about half the students objected to animal research, extend to the general population, the outcome of a referendum about animal experimentation might be finely balanced.

There is a need, then, to inform the public in more detail about animal experimentation, including that which involves the production and use of transgenic animals.

Our results suggest that it would be helpful to dissect the issues, and distinguish between pain, distress and discomfort caused to animals.

\section{Ruaraidh Hill}

Martin Stanisstreet

Edward Boyes

Environmental Education

Research Unit,

University of Liverpool,

Liverpool L69 3BX, UK

e-mail:martstan@liv.ac.uk

Helen O'Sullivan

Department of Environmental

and Biological Studies,

Liverpool Hope University College,

Liverpool L16 9JD, UK 